\title{
Social Cognitive Semantic Conflicts and Social Cognitive Reaction Conflicts: Mechanism of Self-Control
}

\author{
Changxiu Shi' ${ }^{1}$ Xiaojun Zhao ${ }^{2 *}$ \\ ${ }^{1}$ School of Criminal Justice, China University of Political Science and Law, Beijing, China \\ ${ }^{2}$ School of Education, Hebei University, Baoding, China \\ Email: "psy790821@aliyun.com
}

Received 2 March 2016; accepted 10 April 2016; published 13 April 2016

Copyright (C) 2016 by authors and Scientific Research Publishing Inc.

This work is licensed under the Creative Commons Attribution International License (CC BY).

http://creativecommons.org/licenses/by/4.0/

(c) (i)

Open Access

\begin{abstract}
The aims of this study were to investigate the differences in responses for varied self-control experiment paradigms, and to explain these differences on the basis of social cognitive semantic conflicts and social cognitive reaction conflicts. Using two mixed experimental designs, the study incorporated the stop signal and single-attribute implicit association test paradigms into a selfcontrol experiment paradigm to investigate self constructs. Social cognitive semantic conflicts and social cognitive reaction conflicts were significant at 250 - 300 ms post-stimulus. According to different genders, self-control mechanism has universal significance.
\end{abstract}

\section{Keywords}

Self-Control, Stop Signal Task, Single-Attribute Implicit Association Tests, Social Cognitive Conflicts

\section{Introduction}

In the study of the self-control experiment, some researchers use pure cognitive materials as experiment materials. Many of the issues we encounter in daily life are endowed with social significance, and most are self-related stimulations. Conducting a control study lacking in social significance considerably diminishes the breadth and depth of the study. Only a few investigations on the self in relation to social cognitive conflicts have been conducted. The original self monitoring and self-control theory or model (such as the model of self-control strength) failed to consider the conflict of social cognitive level.

${ }^{*}$ Corresponding author. 


\subsection{Mechanism of Self-Control}

The self has been one of the most extensively researched themes in psychology. However, self-control is more important in self study. Self-control refers to an individual's ability to stay committed to goals by suppressing the urge to opt for tempting alternatives, even if these alternatives are based on the self-related need structure (Kuhl, 1996). Self-control helps a person pursue high-priority goals that are not embedded in the personal need structure (Kehr, Bles, \& Rosenstiel, 1999). Experimental studies on the self also contribute to existing literature. For example, research has shown that inhibitions play an important role in cognition, as well as in controlling social and emotional behaviour (Bjorklund \& Harnishfeger, 1995). Social cognitive semantic conflicts and social cognitive reaction conflicts are closely related to executive control. Executive control is typically presumed to facilitate optimal functioning by fuelling actions necessary to override or otherwise change maladaptive tendencies (Baumeister, Heatherton, \& Tice, 1994). Several researchers have introduced different views on the architecture of the executive control system. Processing syntactically difficult sentences accounts for a lengthier executive control process than that observed in processing the simple counterparts of the sentences. This phenomenon prevents refreshing the memory traces of digits, so that these traces more rapidly decay, thereby worsening recall (Loncke, Desmet, Vandierendonck, \& Hartsuiker, 2011). Loncke et al. supported their prediction that executive control is associated with the ability of romantically involved individuals to stay faithful (Pronk, Karremans, \& Wigboldus, 2011). Shuster examined the relationship between five experimental inhibition tasks (Shuster \& Toplak, 2009). To explore the temporal course of neural activity that underlies deception, Shuster recorded event-related potential (ERPs) whilst participants were performing a Differentiation of Deception Paradigm (DDP) task for self and other-referential information (Hua et al., 2011).

\subsection{Study of Self-Control Experiment Paradigms}

From the perspective of self, we selected two typical but different self-control paradigms. The stop signal task (SST), and single-attribute implicit association test (SA-IAT) paradigms were used to investigate self experiment constructs on the basis of what we refer to as social cognitive semantic conflicts and social cognitive reaction conflicts. Conflicts refer to individual explicit or implicit psychological state of struggle. In social cognitive phenomena, the former pertains to conflicts that result from the misunderstanding of words, whereas the latter refers to conflicts that arise from behaviour.

The stop signal paradigm and implicit association test (IAT) have been used in research on the self. Liu established an ideal animal model for studying the etiology and underlying neurobiology of cocaine-induced impulse control and performance-monitoring deficits (Liu et al., 2009). Impairments in motor inhibition were observed in patients with obsessive-compulsive disorder (OCD), but no differences between the motor response performance of patients and controls were found. OCD patients with and without depression did not differ in terms of task performance measures, although significant differences were found in all self-reported measures (MoreinZamir et al., 2010). As discussed by Levina et al. (2011), accumulating evidence suggests that prepulse inhibition deficits may be correlated with impairments in social cognition (i.e. the ability to construct a representation about others, oneself, and the relationship between others and oneself). Senderecka used the stop signal paradigm to determine whether deficient inhibitory control distinguishes children diagnosed with the combined type of attention deficit hyperactivity disorder from normally developing children, matched for age and gender (Senderecka et al., 2012). The Extrinsic Affective Simon Task (EAST) showed low internal consistencies and correlated neither with the IATs nor with the direct measures. The low reliability of the EAST was discussed, and general conclusions regarding the indirect assessment of the personality self-concept through EASTs were derived (Teige et al., 2004). Researchers found higher implicit and explicit anxiety in socially anxious participants (compared with controls) before treatment, and reductions in the IAT-Anxiety and SPAI scores of socially anxious participants after treatment (Gamer et al., 2008). A study suggests that IATs can be used to validly assess the semantic aspect of trait self-concepts and self-representations (Schnabel, Asendorpf, \& Greenwald, 2008). A study revealed positive self-representations in both Japanese and Canadian participants, Japanese participants were found to have significantly lower implicit self-esteem than do Canadians (Szeto, 2009). Scholars explored the psychometric properties of the IAT when it is used in assessing two personality traits within one sample. The implications for the assessment of multiple implicit personality self-concept dimensions were discussed (Konrad et al., 2006a, 2006b). The nonspecific other category in the self-esteem IAT is near neutral in valence (Pinter \& Greenwald, 2005). A new chronometric procedure, the Implicit Association Procedure, was 
adapted to assess the implicit personality self-concept of shyness (Konrad et al., 2006a, 2006b). Greenwald used the IAT to measure self-esteem and self-concept (Greenwald \& Farnham, 2000).

Many researchers conduct the study of self-control phenomenon. However, the studies lack of self-control mechanism; the studies failed to use social cognitive conflict perspective of Self-control phenomenon; experimental materials of the studies use more the pure cognitive materials; the original self monitoring and self-control theory or model failed to consider the conflict of social cognitive level.

\subsection{Current Study}

The model of self-control strength has revealed that it may be effective to promote self-control. The executive component of self (especially, inhibition) depends on a limited, consumable resource (Muraven \& Baumeister, 2000). To fill the gap, the aims of the study were to investigate the differences in responses in varied self experiment paradigms, and to explain these differences on the basis of social cognitive semantic conflicts and social cognitive reaction conflicts.

The specific contents of the experiment materials in previous studies were related primarily to individual character adjectives. Thus, the materials lacked true self-significance in social reality. In the current work, we expanded the materials to include personal name and personal attributes. Social cognitive semantic conflicts and social cognitive reaction conflicts are useful in explaining the practical significance of the self. In social cognition, social cognitive semantic conflicts pertain to those that result from the misunderstanding of words, whereas social cognitive reaction conflicts refer to those that stem from behaviour. The cognition of number about the self falls under social cognition but differs from pure digital cognition. Take age for example. Compared with its significance as a number, its social significance may be more important. When social information on the self is involved, our responses are either social cognitive semantic conflicts or social cognitive reaction conflicts. A more in-depth research on the self was conducted (mechanism of self-control based on social cognitive conflicts). We formulated the following hypotheses: H1: Stop signals played an important role in mechanism of self-control. H2: Task types played an important role in mechanism of self-control. H3: Social cognitive semantic conflicts and social cognitive reaction conflicts were significant at 300 ms post-stimulus. H4: According to different genders, self-control mechanism has universal significance.

\section{Experiment 1: Social Cognitive Reaction Conflicts (SST Paradigm)}

\subsection{Participants}

Twenty-five college students between the ages of 17 and $22(\mathrm{M}=19.2$ years, 15 women and 10 men) participated in the experiment. One additional participant was tested but excluded from the final analyses because he failed to meet the criteria (More than 10\% error rate). All the participants are right-handed and have normal or corrected-to-normal vision.

\subsection{Materials}

The materials contained self information, related non-self information, and general non-self information. Self information included individual name, individual characteristics, individual major (discipline), individual profession of interest, and related words. Related non-self information included roommates' name, roommates' characteristics, profession in popular industries, and related words. Unfamiliar names, non-self characteristics, unpopular or emerging professions, and related words made up general non-self information. All the experiment materials were presented through the DMDX stimulus presentation system (http://www.u.arizona.edu/"jforster/dmdx/DMDX.ZIP). Visual angle is $0.97^{\circ}$ for material. Distance to the screen was $60 \mathrm{~cm}$.

\subsection{Design}

The research was a 2 (gender: male vs. female) $\times 3$ (degree of information pairing: self information vs. general non-self information vs. related non-self information) $\times 3$ (the time at which stop signals appeared: $250 \mathrm{~ms}$ vs. $500 \mathrm{~ms}$ vs. $750 \mathrm{~ms}$ ) mixed experimental design. Gender was a between-group variable; degree of information pairing and the time at which stop signals appeared were within-group variables. The dependent variable was Reaction Time (RT). Data with accuracies of less than $90 \%$ were excluded. In the experiment, we controlled the 
non-self information so that it accords with the level of the self. Some sophomores were selected as subjects for comparison.

\subsection{Procedure}

Psychological research on the self-related information of all the subjects was carried out to ensure the accuracy of information classification. In the campus, the study had a large range of psychological questionnaire survey. The survey mainly involved name, individual characteristics, individual major, roommates' names, good friends' characteristics etc. According to the results of questionnaire, the study made the test material. A month later, the experimenter invited some students have been participated in the questionnaire survey to participate in the experiments. The individual characteristic in experimental materials obtained by subject generation method. Professional or technical name come from the undergraduate professional directory and new undergraduate course list nearly three years of the national ministry of education. Self information, general non-self information, and related non-self information in experimental material must guarantee agreement with participants' information. That is, reaction to the test, experimental material must be part of self information, part of general non-self information, or part of related non-self information. All the characters numbers of vocabulary were controlled in 3 - 5.

All the experiment materials were presented through the DMDX stimulus presentation system, which includes 9 subsystems with the same test frequency of 20 . The subjects were seated $70 \mathrm{~cm}$ away from the computer screen, whose background was black. When a tip-stimulated red "+" appeared, the subjects were instructed to focus on the screen. The "+" stimulus appeared $500 \mathrm{~ms}$. Without stop signals, each stimulus was presented for $1000 \mathrm{~ms}$. The participants were asked to respond by pressing the right arrow key within $1000 \mathrm{~ms}$ using index finger, inter stimulus interval is $2000 \mathrm{~ms}$; otherwise, the system ran the next experiment. A stop signal (i.e. a red is word) appeared on $250 \mathrm{~ms}, 500 \mathrm{~ms}$ or $750 \mathrm{~ms}$ after the test stimulus had been presented. The stop signal was also presented for a duration of $500 \mathrm{~ms}$. Participants didn't need any response when see the stop signal. The probability that stop signals will appear was $50 \%$. RT was automatically recorded.

\subsection{Results}

The results showed that the degree of information pairing $(F(2,46)=2.17, p>0.05)$ and gender $(F(1,23)=0.24$, $p>0.05)$ had no significant effect, whereas the stop signals had a significant effect $(F(2,46)=48.25, p<0.001$, Partial $\eta^{2}=0.68$ ) on RT in the SST paradigm. The interaction between degree of information pairing and time at which the stop signals appeared also exhibited a significant effect $\left(F(4,92)=9.48, p<0.001\right.$, partial $\left.\eta^{2}=0.29\right)$. Difference amongst the three time levels $(250,500$, and $750 \mathrm{~ms})$ was also found $(p<0.001)$. The RT at $750 \mathrm{~ms}$ was the longest, and that at $500 \mathrm{~ms}$ was longer than that at $250 \mathrm{~ms}$. In the analysis of simple effects, those of degree of information pairing were significant at $250 \mathrm{~ms}(p \leq 0.001)$, but nonsignificant at $500 \mathrm{~ms}(p>0.05)$ and $750 \mathrm{~ms}(p>0.05)$ (Figure 1$)$.

\section{Experiment 2: Social Cognitive Semantic Conflicts (SA-IAT Paradigm)}

\subsection{Participants}

Twenty-three college students between the ages of 19 and 23 ( $M=19.8$ years, 10 women and 13 men) participated in this experiment. Four additional participants were tested but excluded from the final analyses because they failed to satisfy the criteria (more than $10 \%$ error rate). All the participants are right-handed and had normal or corrected-to-normal vision.

\subsection{Design}

The research was a 2 (gender: male vs. female) $\times 3$ (degree of information pairing: self information vs. general non-self information vs. related non-self information) $\times 2$ (task type: initial joint task vs. reverse joint task) mixed experimental design. Gender was a between-group variable; degree of information pairing and task type were within-group variables. The dependent variable was RT.

\subsection{Materials}

The materials contained self information, related non-self information, and general non-self information. All the 


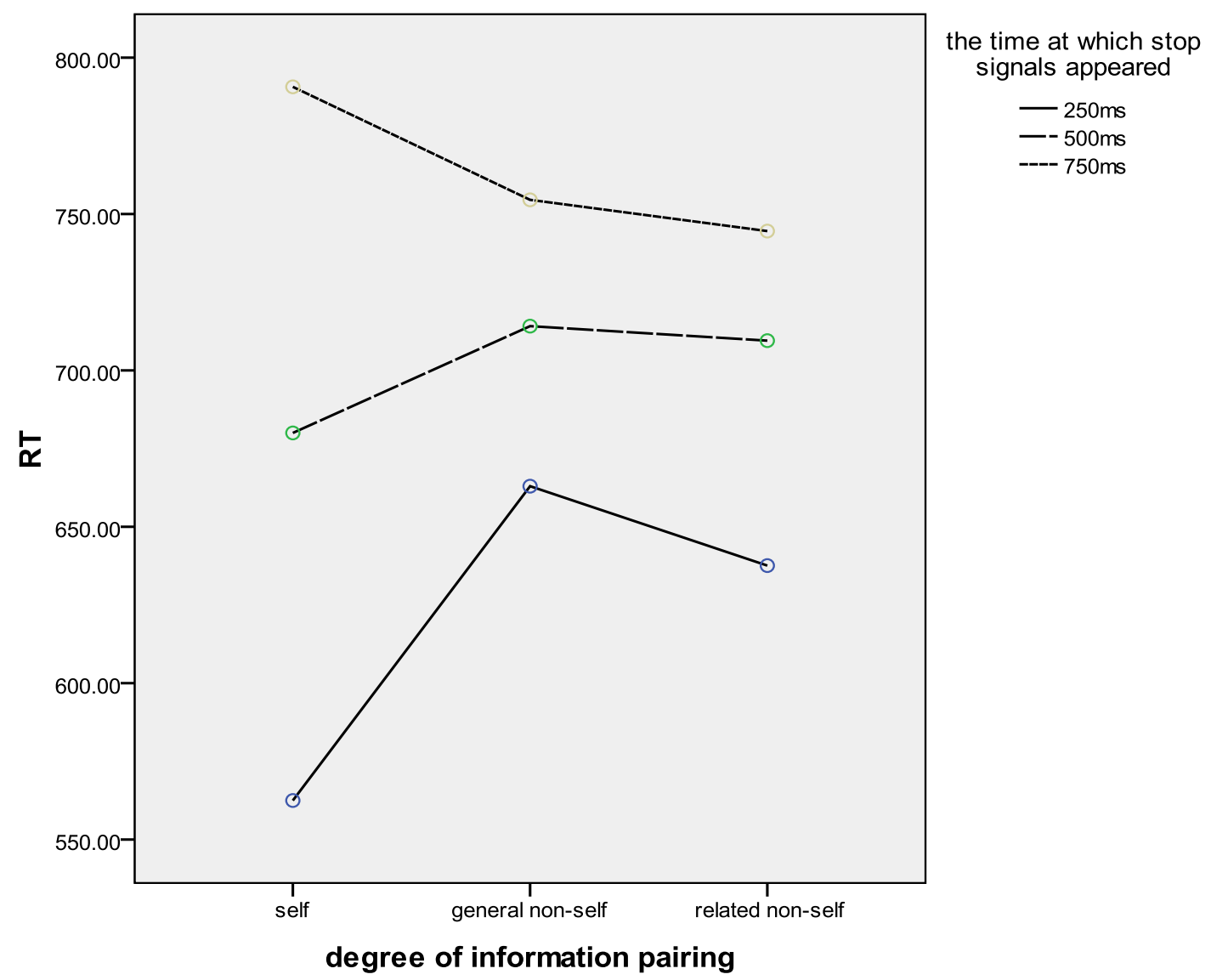

Figure 1. The interaction between degree of information pairing and time at which the stop signals appeared.

experiment materials were presented via the DMDX stimulus presentation system. The sizes of the stimulus materials had default values. The experiment materials were presented by matching concept words and attribute words. The concept words included self words and other words, including "I”, "oneself”, "their own", "he”, and "others". The attribute words included "self information", "related non-self information", and "general non-self information". The concept words were matched with the attribute words to create words such as "I-cheerful", "he-cheerful", and other similar combinations. All the experiment materials were presented through the DMDX stimulus presentation system. Visual angle is $0.97^{\circ}$ for material. Distance to the screen was $60 \mathrm{~cm}$.

\subsection{Procedure}

A psychological survey was conducted to validate the classification of self information, related non-self information, and general non-self information. The experiment materials included 13 subsystems with the same test frequency of 20. During the task identification stage, self words and other words were randomly presented. Subjects were instructed to press the right arrow key $(\rightarrow)$ when a self word appeared and the left arrow key $(\leftarrow)$ when other words were presented. The RT was automatically recorded. After a minute's rest, initial joint task 1 (practice) was started. Self words and other words-general non-self information were randomly presented. When a self word was shown, the participants were asked to press the right shift key; when other words-general non-self information appeared, the participants were asked to press the left arrow key. Initial joint task 1 (official) was then initiated after a minute of rest. Self words and other words-general non-self information were randomly presented. When a self word was shown, the subjects were asked to press the right shift key; when other words - general non-self information appeared, the participants were asked to press the left arrow key. The RT was automatically recorded. After two minutes of rest, we initiated reverse joint task 1 (practice). Self words-general non-self information and other words were also randomly displayed. When self wordsgeneral non-self information appeared, the subjects were asked to respond by pressing the right arrow key; when 
other words appeared, the subjects were asked to respond by pressing the left arrow key. Reverse joint task 1 (official) was then initiated. Similarly, self words-general non-self information and other words were randomly displayed. When self words-general non-self information appeared, the participants were asked to press the right arrow key; when other words appeared, the participants were asked to press the left arrow key. The RT was automatically recorded. After two minutes of rest, we conducted the next experiment system. The practice and formal initial joint test and practice and formal reverse joint test operations were repeated. The experiment was conducted to generate results for all the components of related non-self information and general non-self information. Each stimulus was presented for $1000 \mathrm{~ms}$. The participants were asked to respond within $1000 \mathrm{~ms}$, inter stimulus interval is $2000 \mathrm{~ms}$. The RT was automatically recorded.

\subsection{Results}

The results showed that degree of information pairing in the SA-IAT paradigm had a significant effect on the reaction $\left(F(2,42)=3.46, p<0.05\right.$, partial $\left.\eta^{2}=0.14\right)$. By contrast, task type $(F(1,21)=1.60, p>0.05)$ and gen$\operatorname{der}(F(1,21)=.01, p>0.05)$ had no significant effects. The interaction amongst degree of information pairing, task type, and gender was significant $\left(F(2,42)=4.96, p<0.05\right.$, partial $\left.\eta^{2}=0.19\right)$. The post hoc test showed that amongst the three levels of degree of information pairing (self information, related non-self information, general non-self information), the difference between self information and general non-self information was significant $(p<0.01)$. Moreover, the RT for general non-self information was longer than did the RT for self information. The simple effect of degree of information pairing was significant at the initial level $(p<0.01)$ and nonsignificant at the reverse level $(p>0.05)$. For the female participants, the simple effect was nonsignificant in all levels of degree of information pairing $(p>0.05)$. For the male subjects, the simple effect was significant in all levels of degree of information pairing $(p \leq 0.01)$ (Figure 2).

\section{Discussion}

\subsection{Mechanism of Self-Control}

Social cognitive semantic conflicts and social cognitive reaction conflicts are possibly mechanisms of self-control. In these two types of conflicts, the goals of the specific experiments were attained. However, these conflicts were joined in the experiments, thereby suppressing participant responses. Social cognitive conflicts cannot be categorised under the personal need structure; they can only be transformed into self-control mechanisms, a contention that requires further study.

Experimental studies on the self also contribute to existing literature. For example, research has shown that inhibitions play an important role in cognition, as well as in controlling social and emotional behaviour (Bjorklund \& Harnishfeger, 1995). Social cognitive semantic conflicts and social cognitive reaction conflicts are closely related to executive control. Executive control is typically presumed to facilitate optimal functioning by fuelling actions necessary to override or otherwise change maladaptive tendencies (Baumeister, Heatherton, \& Tice, 1994). Several researchers have introduced different views on the architecture of the executive control system. Processing syntactically difficult sentences accounts for a lengthier executive control process than that observed in processing the simple counterparts of the sentences. This phenomenon prevents refreshing the memory traces of digits, so that these traces more rapidly decay, thereby worsening recall (Loncke, Desmet, Vandierendonck, \& Hartsuiker, 2011). Loncke et al. supported their prediction that executive control is associated with the ability of romantically involved individuals to stay faithful (Pronk, Karremans, \& Wigboldus, 2011). Shuster examined the relationship between five experimental inhibition tasks (Shuster \& Toplak, 2009). To explore the temporal course of neural activity that underlies deception, Shuster recorded ERPs whilst participants were performing a DDP task for self and other-referential information (Hua et al., 2011).

Social cognitive semantic conflicts and social cognitive reaction conflicts are related to the capacity for executive control. The first individual reaction in the SST paradigm is a type of social cognitive reaction conflict affected by the physical significance of the stimulus. With increasing time, however, the social cognitive semantic conflicts and social cognitive reaction conflicts linked them. The information on the individual self showed that social cognitive semantic conflicts and social cognitive reaction conflicts were balanced at $250-300 \mathrm{~ms}$ in the SA-IAT paradigm. Within working memory, the hands and brain functioned in a competitive manner in the central executive system. Social cognitive semantic conflicts are classified under top-down processing, whereas social cognitive reaction conflicts are categorised under bottom-up processing. To achieve good scores, indi- 
viduals should be able to automatically switch between social cognitive semantic conflicts and social cognitive reaction conflicts. Overcoming the obstacles to understanding words and barriers to timely hand reaction necessitates controlling the situation to achieve balance.

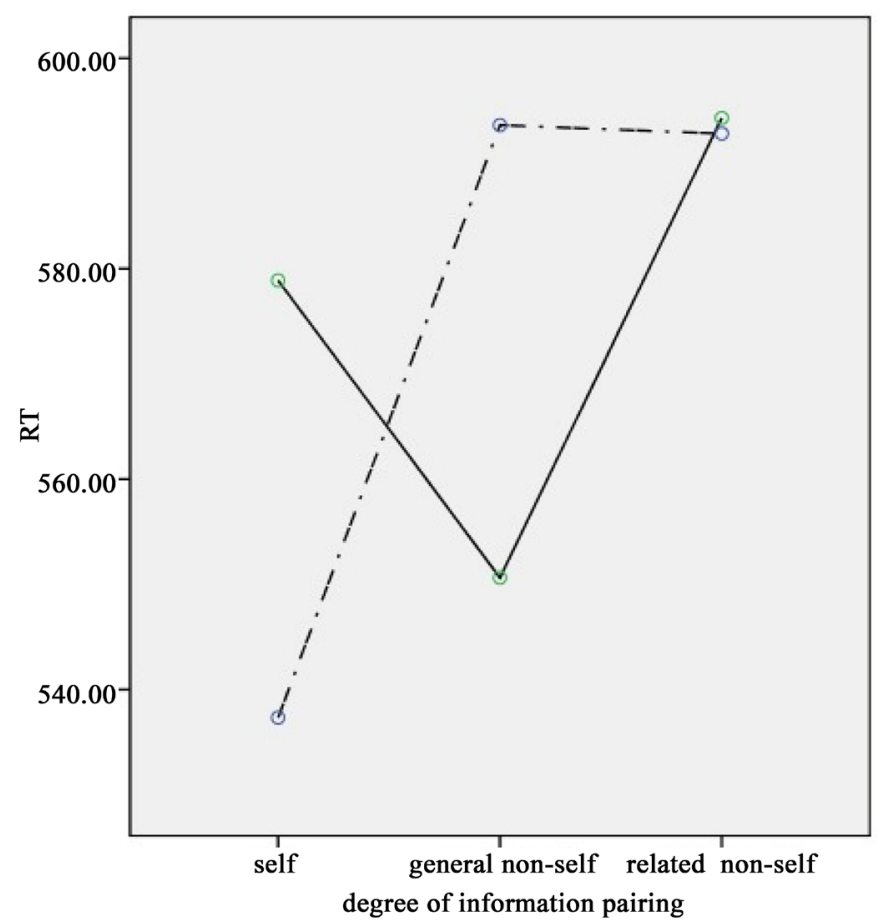

task type

- initial joint

- reverse joint

(a) Male

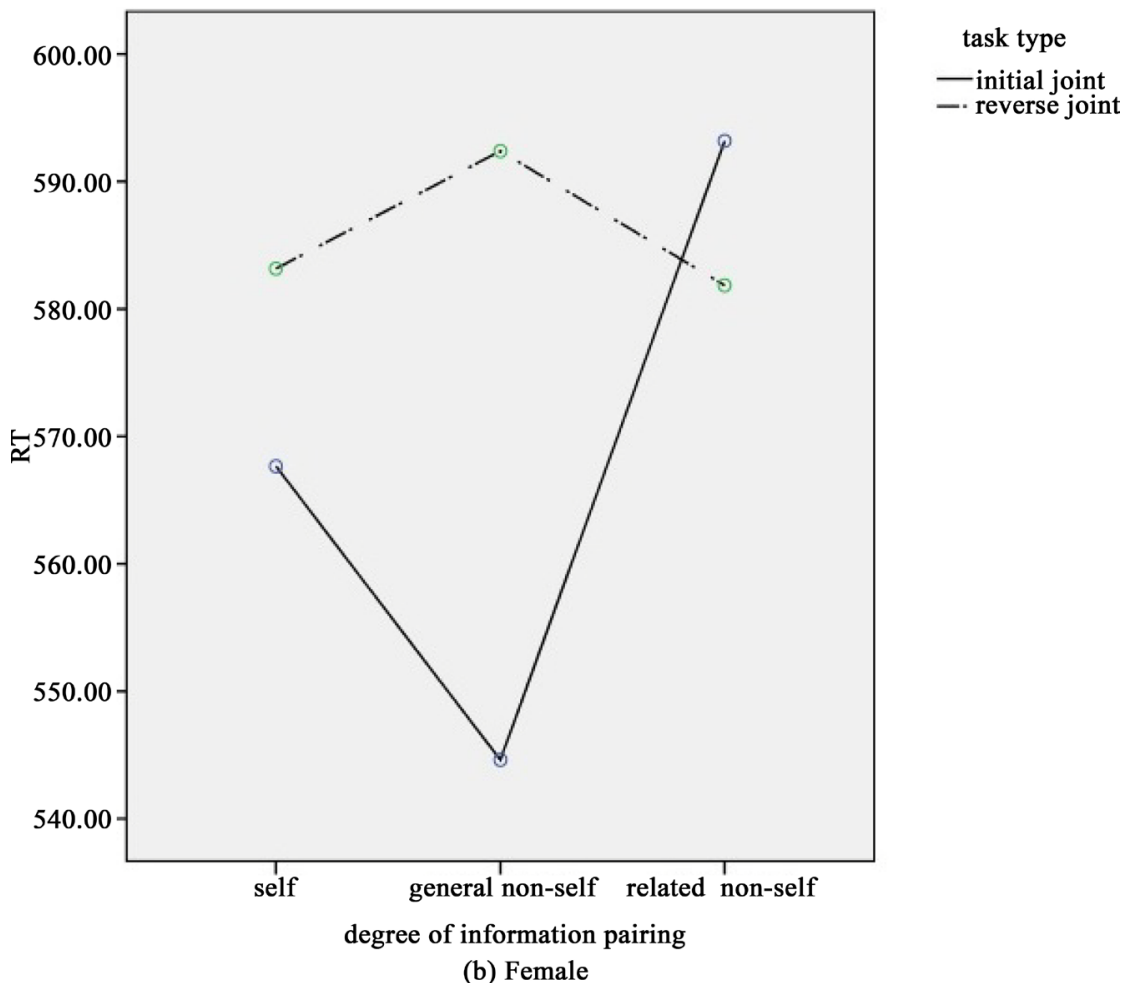

Figure 2. The interaction amongst degree of information pairing, task type, and gender. 


\subsection{Social Cognitive Reaction Conflicts in the SST Paradigm}

In the SST paradigm, the time at which the stop signals appeared affected the RT for self information; the RT at $250 \mathrm{~ms}$ level was the shortest. That is, at $250 \mathrm{~ms}$ up to the time accurate results were obtained, the RT for the three kinds of information was the shortest. The cognition of number about the self falls under social cognition but is different from digital cognition. The reaction to general information may be related to cognitive semantic conflicts and cognitive reaction conflicts. Our responses to social information on the self should be either social cognitive semantic conflicts or social cognitive reactions conflicts. From a researcher's point of view, the identity of self-matching is related to social cognitive problems. Social cognitive conflicts can be divided into social cognitive semantic conflicts and social cognitive reaction conflicts. In the SST paradigm, we symbolized stop signals as only a kind of physical stimulation. The first individual reaction in the SST paradigm is a kind of social cognitive reaction conflict affected by the physical significance of the stimulus; that is, external activities. With increasing time, however, a rising number of individual reactions were affected by internal self-schemata. Ideas related to self-understanding increased and linked by social cognitive semantic conflicts and social cognitive reaction conflicts.

\subsection{Social Cognitive Semantic Conflicts in the SA-IAT Paradigm}

Before treatment, implicit self-anxiety associations are stronger in socially anxious participants than in a control group of non-anxious individuals. Furthermore, cognitive-behavioural therapy for social anxiety is associated with reduced implicit self-anxiety associations (Gamer et al., 2008). The results of those studies showed that the IAT is suitable for assessing specific semantic self-associations that cannot be interpreted as indicators of implicit self-esteem (Schnabel, Asendorpf, \& Greenwald, 2008). In the SA-IAT paradigm, the experimental programme revealed that the individual reaction was based primarily on social cognitive semantic conflicts. This experiment was conducted without a guiding process involving physical stimulation; stimulation was related directly to the self. Moreover, the RT for general non-self information was longer than that for self-information. Implicit self-matching was faster than implicit non-self-matching. The analysis of the simple effect showed that the simple effect of degree of information pairing was remarkable at the initial level (initial joint task 1); self words and other self information words were randomly shown. When a self word and other self information words were shown, the subjects pressed the right shift key and left arrow key, respectively. For the male subjects, the simple effect was notable in all levels of degree of information pairing. The statistical graph shows that at the initial level, the RT of the males for self information was considerably shorter than that for related non-self information and general non-self information. When self factors were involved, the social cognitive semantic conflicts and social cognitive reaction conflicts of males decreased, and the inclination towards social information on the self strengthened. At the reverse level, the practice effect was more likely to offset the various differences between the self materials. Additionally, the self-reference effect was related more strongly to cognitive memory. Social cognitive semantic conflicts were also related to the self-reference effect. The self information, related non-self information, and general non-self information were matched, including information in cognitive memory. The memory of the self-reference effect reinforced the time spent in task processing; hence, the general non-self information referred to self information, reasoning, and memory transmission, which extended the RT.

\subsection{Social Cognitive Semantic Conflicts and Social Cognitive Reaction Conflicts at 250 - $300 \mathrm{~ms}$}

At 250 ms, self or non-self constructs that involved relevant social cognitive semantic conflicts and social cognitive reaction conflicts exhibited the least significant effect, and reached a temporary balance in the SST paradigm. Furthermore, at $250 \mathrm{~ms}$, the RT for self-matched information is shorter than that for general non-self information and related non-self information because the $250 \mathrm{~ms}$ signal is significant in the recognition of matched self-information. Motor inhibition impairments were observed in OCD patients, whereas no difference in the motor response performance of patients and controls was found. Switching to a new response rather than motor inhibition was affected by stimulus relevant to the OCD patients (Morein-Zamir et al., 2010). For children with ADHD, terminating response is easier in conflict conditions than in consistent conditions at SOA of 250 and $400 \mathrm{~ms}$ (Wang et al., 2005). The current work showed the significance of the appearance of stop signals at 
around $250 \mathrm{~ms}$ in a more detailed manner. The time at which the stop signals appeared may be a result of the matching of self-information (e.g. individual profession). The social cognitive semantic conflicts and social cognitive reaction conflicts were minimised. In the SA-IAT paradigm, the subjects attempted to register a response reflecting two self attributes: the RT at 500 and $600 \mathrm{~ms}$. The information on the individual self showed that the social cognitive semantic conflicts and social cognitive reaction conflicts were balanced at 250 - $300 \mathrm{~ms}$.

\subsection{Research Limitations and Future Studies}

Although our findings support our hypotheses, other features of the visual self may have influenced the results. One factor may be participant selection; another is the contention in cognitive neuroscience that social cognitive semantic conflicts and social cognitive reaction conflicts are balanced at $250-300 \mathrm{~ms}$. The researchers need to validate the study by new paradigms. The study needs to check following results through cognitive neuroscience method. Social cognitive semantic conflicts and social cognitive reaction conflicts were significant at $250-300$ ms post-stimulus. The study can reform material and experimental design by using augmented reality technology to improve the ecological validity.

\section{Acknowledgements}

This study was supported from graduate student innovation fund of China University of Political Science and Law (psychological emotion), fund number is 2015BSCX22.

\section{References}

Baumeister, R. F., Heatherton, T. E., \& Tice, D. M. (1994). Losing Control: How and Why People Fail at Self-Regulation. San Diego, CA: Academic Press.

Bjorklund, D. F., \& Harnishfeger, K. K. (1995). The Evolution of Inhibition Mechanisms and Their Role in Human Cognition and Behavior. In F. N. Dempster, \& C. J. Brainerd (Eds.), Interference and Inhibition in Cognition (pp. 141-173). San Diego, CA: Academic Press. http://dx.doi.org/10.1016/B978-012208930-5/50006-4

Gamer, J., Schmukle, S. C., Luka-Krausgrill, U., \& Egloff, B. (2008). Examining the Dynamics of the Implicit and the Explicit Self-Concept in Social Anxiety: Changes in the Implicit Association Test-Anxiety and the Social Phobia Anxiety Inventory Following Treatment. Journal of Personality Assessment, 90, 476-480. http://dx.doi.org/10.1080/00223890802248786

Greenwald, A. G., \& Farnham, S. D. (2000). Using the Implicit Association Test to Measure Self-Esteem and Self-Concept. Journal of Personality and Social Psychology, 79, 1022-1038. http://dx.doi.org/10.1037/0022-3514.79.6.1022

Hua, X. Q., Wu, H. Y., \& Fu, G. Y. (2011). Temporal Course of Executive Control When Lying about Self- and Other-Referential Information: An ERP Study. Brain Research, 1369, 149-157. http://dx.doi.org/10.1016/j.brainres.2010.10.106

Kehr, H. M., Bles, P., \& Rosenstiel, L. (1999). Self-Regulation, Self-Control, and Management Training Transfer. International Journal of Educational Research, 31, 487-798. http://dx.doi.org/10.1016/s0883-0355(99)00017-8

Konrad, S., Rainer, B., \& Jens, A. (2006a). Assessment of Implicit Personality Self-Concept Using the Implicit Association Test (IAT): Concurrent Assessment of Anxiousness and Angriness. British Journal of Social Psychology, 45, 373-396. http://dx.doi.org/10.1348/014466605X49159

Konrad, S., Rainer, B., \& Jens, A. (2006b). Employing Automatic Approach and Avoidance Tendencies for the Assessment of Implicit Personality Self-Concept: The Implicit Association Procedure (IAP). Experimental Psychology, 53, 69-76. http://dx.doi.org/10.1027/1618-3169.53.1.69

Kuhl, J. (1996). Wille und Freiheitserleben: Formen der selbststeuerung. In J. Kuhl, \& H. Heckhausen, Enzyklopädie der psychologie, serie Motivation und emotion, Bd. 4: Motivation, volition und handlung (pp. 665-765). Göttingen: Hogrefe.

Levina, R., Rachel, B. M., Lichtenberg, P. et al. (2011). Defensive Self-Presentation Style Is Associated with Reduced Prepulse Inhibition. European Neuropsychopharmacology, 21, 810-813. http://dx.doi.org/10.1016/j.euroneuro.2010.12.009

Liu, S. J., Heitzd, R. P., \& Bradberry, C. W. (2009). A Touch Screen Based Stop Signal Response Task in Rhesus Monkeys for Studying Impulsivity Associated with Chronic Cocaine Self-Administration. Journal of Neuroscience Methods, 177, 67-72. http://dx.doi.org/10.1016/j.jneumeth.2008.09.020

Loncke, M., Desmet, T., Vandierendonck, A., \& Hartsuiker, R. J. (2011). Executive Control Is Shared between Sentence Processing and Digit Maintenance: Evidence from a Strictly Timed Dual-Task Paradigm. Journal of Cognitive Psychology, 23, 886-911. http://dx.doi.org/10.1080/20445911.2011.586625

Morein-Zamir, S., Fineberg, N. A., Robbins, T.W., \& Sahakian, B. J. (2010). Inhibition of Thoughts and Actions in Obses- 
sive-Compulsive Disorder: Extending the Endophenotype? Psychological Medicine, 40, 263-272. http://dx.doi.org/10.1017/S003329170999033X

Muraven, M., \& Baumeister, R. F. (2000). Self-Regulation and Depletion of Limited Resources: Does Self-Control Resemble a Muscle? Psychological Bulletin, 126, 247-259. http://dx.doi.org/10.1037/0033-2909.126.2.247

Pinter, B., \& Greenwald, A. G. (2005). Clarifying the Role of the "Other" Category in the Self-Esteem IAT. Experimental Psychology, 52, 74-79. http://dx.doi.org/10.1027/1618-3169.52.1.74

Pronk, T. M., Karremans, J. C., \& Wigboldus, D. J. (2011). How Can You Resist? Executive Control Helps Romantically Involved Individuals to Stay Faithful. Journal of Personality \& Social Psychology, 100, 827-837. http://dx.doi.org/10.1037/a0021993

Schnabel, K., Asendorpf, J. B., \& Greenwald, A. G. (2008). Understanding and Using the Implicit Association Test: V. Measuring Semantic Aspects of Trait Self-Concepts. European Journal of Personality, 22, 695-706. http://dx.doi.org/10.1002/per.697

Senderecka, M., Grabowska, A., Szewczyk, J. et al. (2012). Response Inhibition of Children with ADHD in the Stop-Signal Task: An Event-Related Potential Study. International Journal of Psychophysiology, 85, 93-105. http://dx.doi.org/10.1016/j.ijpsycho.2011.05.007

Shuster, J., \& Toplak, M. E. (2009). Executive and Motivational Inhibition: Associations with Self-Report Measures Related to Inhibition. Consciousness and Cognition, 18, 471-480. http://dx.doi.org/10.1016/j.concog.2009.01.004

Teige, S., Schnabel, K., Banse, R., \& Asendorpf, J. B. (2004). Assessment of Multiple Implicit Self-Concept Dimensions Using the Extrinsic Affective Simon Task (EAST). European Journal of Personality, 18, 495-520.

http://dx.doi.org/10.1002/per.531

Wang, Y. H., Zhou, X. L., Wang, Y. F., \& Zhang, Y. X. (2005). Response Inhibition in Two Subtypes of Children with ADHD. Chinese Acta Psychologica Sinica, 37, 178-188. 